\title{
Educação física e esporte: reflexões e ações contemporâneas
}

\author{
André Silva Mello* \\ Omar Schneider ${ }^{* *}$ \\ Wagner dos Santos ${ }^{* * *}$ \\ Sebastião Josué Votre ${ }^{* * * *}$ \\ Amarílio Ferreira Neto ${ }^{* * * * *}$
}

Resumo: $O$ artigo analisa o modo como os sujeitos se apropriam do esporte, sinalizando outras possibilidades para compreender as relações com as práticas esportivas. Para tanto, entrevista 83 sujeitos, 69 evadidos e 14 participantes de um projeto social. A análise indica que os participantes aceitaram, por tempo limitado, ou mesmo rejeitaram a proposta do projeto, fundamentada na concepção crítico-superadora. Percebe-se não apenas a reprodução, nem tampouco a adaptação às regras, mas um uso que permitiu a participação produtiva realizada na dialética das estratégias impostas pelo projeto, em relação às táticas de subversão dos participantes que decidiram abandoná-lo ou nele permanecer.

Palavras-chave: Esportes. Educação Física. Reflexões. Ações.

\footnotetext{
"Centro de Educação Física e Desportos da Universidade Federal do Espírito Santo. E-mail: andremellovix@gmail.com

"Centro de Educação Física e Desportos da Universidade Federal do Espírito Santo. E-mail: omar@proteoria.org

"'Centro de Educação Física e Desportos da Universidade Federal do Espírito Santo. E-mail: wagner@proteoria.org

.... Universidade Federal do Rio de Janeiro, Programa de Pós-Graduação da Universidade Gama Filho. E-mail: sebastianovotre@yahoo.com

-...*."Pós-Graduação do Centro de Educação Física e Desportos da Universidade Federal do Espírito Santo. E-mail: amarilio@proteoria.org
} 


\section{INTRODUÇÃO}

Nos últimos dez anos, aumentou a produção acadêmica sobre o esporte. $\mathrm{O}$ debate se revigorou em diferentes perspectivas teóricas e epistemológicas, com novos questionamentos para a Educação Física e novas possibilidades de interpretação sobre o tema.

Nesse contexto, alguns autores da Educação Física, assim como o discurso midiático preconizam o papel da Educação Física na deteç̧ão e formação de atletas, e parte do meio acadêmico critica a reprodução dos valores associados ao esporte de rendimento na escola, julgando-os atrelados ao modo de produção capitalista, perpetuando as condições de exploração e injustiças sociais.

Ambas as atitudes se fundamentam na produção discursiva que dicotomiza o esporte como bom/ruim, alienação/conscientização, sem compreender o que o esporte representa para seus praticantes.

São múltiplas as possibilidades para a tematização do objeto, pois o esporte é um fenômeno polissêmico. Em cada possibilidade, há controvérsias. ${ }^{1}$ As críticas, incisivas na década de 1990, reverberam no contexto acadêmico atual, constituindo-se como referências para entender a relação entre Educação Física, formação profissional e esporte. $^{2}$

O que propomos neste estudo é outra análise do fenômeno esportivo, que nos permite compreender o que as pessoas fazem com os produtos culturais que lhes são oferecidos ao consumo. Nessa perspectiva, objetivamos analisar as práticas discursivas de 14 participantes e de 69 evadidos do Projeto Esporte Cidadão (PEC).

\footnotetext{
'O fenômeno esportivo, nos anos finais do século XIX, já recebia críticas do movimento anarquista, como pode ser percebido no jornal A Voz do Trabalhador e em outros impressos. Nas décadas de 1930 e 1940, a revista Educação Physica analisa a substituição da ginástica como conteúdo da Educação Física pelos esportes, em alguns momentos fazendo uma apreciação crítica e em outros demonstrando entusiasmo pela esportivização da cidade e da instituição escolar (SCHNEIDER, 2004).

${ }^{2}$ Ver a seção Temas Polêmicos na Revista Movimento, bem como no livro de Stigger e Lovisolo (2009).
} 
O PEC é um projeto de intervenção social, que oferece atividades físicas e esportivas, desenvolvido por meio de convênio entre o Curso de Educação Física, Esporte e Lazer, do Centro Universitário Vila Velha/ES, e a Secretaria de Educação desse município. O projeto foi implantado em uma escola pública de Soteco, bairro periférico da cidade, e foi concebido pelos seus gestores para atuar na perspectiva crítico-superadora (SOARES et al., 1992). Entre os anos de 2001 e 2007, o projeto atendeu a uma média de 400 adolescentes e jovens.

Os dados foram produzidos por meio de entrevistas semiestruturadas e foram interpretados pela Análise Crítica do Discurso (FAIRCLOUGH, 2001; WODAK; MAYER, 2001; VAN DIJK, 2000), que focaliza a relação dialética entre o discurso e a sociedade, explicitando as representações que se manifestam em favor daqueles que se encontram em desvantagem nas relações de poder.

Inicialmente, focalizamos algumas críticas formuladas na Educação Física brasileira em relação à apropriação do esporte educacional, para compreender a abordagem que circulou e circula robusta nos cursos de formação em Educação Física do País. Valemo-nos da noção de consumo produtivo (CERTEAU, 1994) para refutar a hipótese de que há reprodução mecânica dos valores capitalistas por parte de quem pratica esporte. Posteriormente, anunciamos outra possibilidade para compreender as relações que os sujeitos estabelecem com as práticas esportivas em diferentes figuras do aprender (CHARLOT, 2000), dando visibilidade aos usos que os atores sociais fazem do esporte, sem o definirmos a priori. Por fim, analisamos os discursos de evadidos e de participantes do PEC sobre a prática esportiva no contexto do projeto. 


\section{ESPORTE, SOCIEDADE E CIDADANIA: REFLEXÕES E AÇÕES CONTEMPO- RÂNEAS}

"A criança que pratica esporte respeita as regras do jogo... capitalista" (BRACHT, 1986, 1992). Em consonância com as interpretações presentes no meio acadêmico da Educação e da Educação Física, derivadas das apropriações da Teoria Marxista, esta tese das consequências da adesão ao fenômeno esportivo atravessa a década de 1990. Os saberes socializados pelo esporte são interpretados como "[...] reflexo mediatizado da estrutura social em que ele se realiza, ou seja, da sociedade capitalista" (BRACHT, 1992, p. 64), e o esporte realizado na escola, prossegue o autor, é visto como "[...] uma forma de controle social, pela adaptação do praticante aos valores e normas dominantes como condição alegada para a funcionalidade e desenvolvimento da sociedade" (p. 64).

O esporte de rendimento, além de exercer um papel funcionalista para a reprodução do capitalismo, alienaria, como na política do "pão e circo", e desviaria a atenção da população dos aspectos políticos e sociais relevantes em detrimento de atividades supérfluas.

A Educação e a Educação Física, nessa ótica, permitem e favorecem a reprodução do sistema de classes e da sociedade como uma invenção da ideologia burguesa, que, para se manter como elite, investe em mecanismos de controle, que fazem suas ideias se tornarem hegemônicas por dispositivos como a escola e o esporte. Essa lógica interpretativa tem em Bourdieu e Passeron (1982), Althusser (1985) e Foucault (1987) os seus principais interlocutores, nem sempre categoricamente afinados em suas referências, mas explicitados na coerência interna das narrativas propostas naquele contexto. $^{3}$

\footnotetext{
${ }^{3}$ As críticas geradas nesse processo são encontradas em Esporte de rendimento e esporte na escola (VAZ, 2009).
} 
Leitura fácil das últimas três décadas do século $\mathrm{XX}$, as teses marxistas e reprodutivistas criam o espetáculo da denúncia, desvelam a cortina e materializam o script da crítica radical ao sistema. Esse movimento é uma descoberta tardia do pensamento pós-vendaval de 1968, na Educação Física brasileira, como demonstra Castellani Filho em entrevista concedida a Ferreira Neto (1996). O tema da crise da Educação Física se torna o mote que orienta a desconstrução dos discursos que afirmavam o esporte como conteúdo a ser ensinado na instituição educacional (MEDINA, 1983).

Como alternativa às interpretações correntes, que polarizam a compreensão e apropriação do fenômeno esportivo em binômios dicotômicos (alienador/conscientizador; excludente/emancipatório), propomos analisar o esporte na perspectiva dos seus praticantes, dando-lhes "voz" para que expressem o consumo produtivo que fazem dessa manifestação cultural. Para isso, utilizamos a chave interpretativa proposta por Certeau (1994) e Chartier (1994) sobre a invenção do cotidiano e as possibilidades de uma estética da recepção preocupada em compreender as operações furtivas dos consumidores em frente aos bens culturais. Essa estética da recepção considera as operações empregadas pelos praticantes, tanto de rebeldia como de vadiagem, que operam nos limites de uma dialética das estratégias ${ }^{4}$ de imposição de sentido e das práticas/ táticas de apropriação ${ }^{5}$ das mensagens culturais veiculadas por diferentes agências de socialização, como a família, a escola e a mídia.

Segundo Certeau (1994), os consumidores utilizam diferentes maneiras e artes de fazer para dar vida a um incessante trabalho de fabricação de significados pessoais, que muitas vezes ficam escondidos e silenciados. O autor propõe, portanto, uma leitura para

\footnotetext{
${ }^{4}$ Para Certeau (1994, p. 46), a estratégia é "[...] o cálculo das relações de forças que se torna possível a partir do momento em que um sujeito de querer e poder é isolável de um 'ambiente'. O conceito postula um lugar capaz de ser circunscrito como um próprio e portanto capaz de servir de base à gestão de suas relações com uma exterioridade distinta".

${ }^{5}$ Segundo Certeau (1994, p. 46-47), "[...] a tática depende do campo do outro. Joga lance a lance, na busca de auferir ganho. Pode-se dizer que a tática está em movimento permanente (capta no vôo) para auferir legitimidade no campo do outro, o que lhe garante um não-lugar estratégico".
} 
a atividade de recepção ativa, na qual os consumidores desenvolvem ações, fabricam formas alternativas de uso dos bens culturais, produzindo outros sentidos para além das estratégias impostas.

Discutiremos uma experiência de intervenção pedagógica associada às atividades esportivas desenvolvida no PEC que, inicialmente, fora concebida na perspectiva crítico-superadora, mas que mudou os rumos de suas ações em reação ao movimento de saída e voz dos seus participantes. Hirschman (1973, p. 16-17) postula que esses dispositivos são capazes de acionar mudanças nas instituições ao afirmar:

Alguns membros deixam a organização: é a opção de saída. [...] os membros da organização expressam sua insatisfação diretamente à direção, a uma autoridade à qual a direção esteja subordinada, ou através de protestos gerais, dirigidos a quem estiver interessado em ouvi-los: é a opção de voz.

A voz, para o autor, ativa a lealdade, capitalizando a opinião dos insatisfeitos na promoção das alterações necessárias para o redirecionamento das instituições

Então, como regra, a lealdade põe de lado a saída e ativa a voz. É verdade que, frente ao descontentamento com o estado da organização, um membro pode continuar fiel mesmo que, pessoalmente, não seja influenciado, contando que alguém vai agir ou que alguma coisa vai acontecer para melhorar a situação (HIRSCHMAN, 1973, p. 83).

A análise do PEC nos propicia ensaiar outra leitura dos usos do esporte na formação e, ao mesmo tempo, perspectivar a relação com os saberes que podem se tornar referências para o trato pedagógico do esporte. Para Charlot (2000), estudar a relação com o saber é estudar o homem confrontado com a necessidade de aprender a lidar com diversos tipos de saber. Em seus termos, a relação com o saber é "[...] a relação com o mundo, com o outro e com ele mesmo, de um sujeito confrontado com a necessidade de aprender" (CHARLOT, 2000, p. 80). 
Para o autor, as relações com os saberes podem originar diferentes figuras do aprender e essas se encontram em três formas de relação com o saber. A relação objetivação-denominação referese à apropriação de conceitos, de fórmulas, de abstrações produzidas pelos homens e que se constituem como capital simbólico da humanidade. A segunda relação com o saber pode ocorrer no domínio de uma atividade. Não é a posse de um saber-objeto, como na relação anterior, mas o domínio de uma determinada atividade que tem o corpo como lugar de apropriação do mundo. Essa relação é denominada de imbricação do eu, "[...] em que o aprender é o domínio de uma atividade engajada no mundo que se inscreve no corpo. $\mathrm{O}$ corpo é um lugar de apropriação do mundo, um conjunto de significações vivenciadas" (CHARLOT, 2000, p. 69). Na terceira figura do aprender, distanciação regulação, quem aprende é o sujeito afetivo e relacional, constituído por sentimentos e emoções em situação e em ato. É das relações e situações que se forma um sujeito encarnado, temporal e provido de afetividade.

\section{Projeto ESPORTE CIDADÃo: ENTRE AS ESTRATÉGIAS INSTITUCIONAS E AS TÁTICAS DOS PRATICANTES}

O foco das nossas análises são os discursos dos participantes e dos evadidos do PEC. A proposta pedagógica inicial do PEC foi concebida para formar cidadãos críticos, participativos e autônomos, visando ao processo de emancipação social (SOARES et al., 1992). Com orientação socioeducativa, opção explicitada por seus mentores e coordenadores, os objetivos do projeto estavam relacionados com o contexto social mais amplo, com vistas a torná-lo instrumento de análise crítica da realidade, contribuindo para o desenvolvimento pessoal e social dos participantes. De acordo com as orientações pedagógicas do PEC, o esporte era abordado na perspectiva da inclusão social, em que valores, como seletividade e exclusão, visando ao desempenho, eram substituídos por participação e solidariedade.

Enquanto a equipe estava envolvida nos processos de implantação de rotinas e estratégias de gerenciamento das atividades 
de cunho crítico-superador, os jovens se evadiam numa proporção que se revelou preocupante, quando de uma avaliação institucional do projeto, no curso de três anos. A análise das fichas de matrícula do PEC, no período de 2002 a 2005, demonstrou que a média de retenção de participantes de um ano para o outro era de $9,4 \%$, o que significa que $90,6 \%$ abandonavam o projeto no período de um ano, muitos deles não permanecendo mais do que um trimestre.

A partir dessa avaliação, notou-se a necessidade de ouvir os interessados que permaneciam no projeto e avaliar, na análise de suas vozes, o que podia continuar e o que precisava ser reformulado. Por outro lado, devido ao número elevado de participantes que abandonaram o projeto, chegou-se à conclusão de que também fazia sentido ouvir os evadidos.

Constatamos que sete, dos 14 participantes, e 36, dos 69 jovens evadidos do PEC consideraram o aprendizado de uma modalidade esportiva ou de um gesto técnico como o principal benefício proporcionado pelo projeto, conforme ilustram as seguintes falas:

Evadido: [...] pratiquei o nado borboleta, costas. Eu só sabia nadar crawl, aí eu aprendi outros tipos de nado.

Evadido: Aprendi a praticar bem os esportes [...].

Participante: [...] eu conheci modalidades que nunca tinha praticado, tipo a natação, que era conhecida como modalidade de elite [...]. O atletismo também, que, apesar de ser muito conhecido, fazer ele com técnica é totalmente diferente do que você correr na rua $[\ldots]$.

Os interlocutores mostraram que estão conscientes das mudanças que se processaram em suas vivências, a partir das relações que travaram com outros personagens e atores de ensino. Atribuem sentido às vivências no projeto, com base na experiência que estabeleceram com ele. Os verbos utilizados nas falas citadas aprendi, conheci, pratiquei - indiciam as formas com que as figuras do aprender são valorizadas pelos entrevistados. Essas figuras ratificam o modelo de aquisição de saberes de domínio de uma 
modalidade esportiva, numa dimensão identitária. Nos termos de Charlot (2000, p. 72), "[...] aprender faz sentido por referência à história do sujeito, às suas expectativas, à sua concepção de vida $[\ldots]^{\prime \prime}{ }^{6}$

Além disso, é possível identificar, na fala de um entrevistado, que a aprendizagem de novas modalidades esportivas indica que o projeto melhorou a autoestima, o bem-estar e empoderou o entrevistado: "[...] essas modalidades melhoram a minha autoestima. Eu tô evoluindo, tô conseguindo objetivos que nunca imaginei que poderia conseguir $[\ldots] "$.

O alcance desses resultados se dá na fase remodelada do PEC, cuja filosofia inicial estava distante da busca da excitação e da busca da emoção e do gosto. Para Elias e Dunning (1987) e Elias (1994), o processo civilizador reduziu as excitações sérias, que são ameaçadoras à convivência coletiva, aumentando a função compensadora da excitação agradável, cuja apropriação é consciente e socialmente aceita. $\mathrm{O}$ esporte moderno seria uma possibilidade de excitação e resposta de maneira catártica e controlada à emoção mimética das relações, riscos e tensões do cotidiano. Lovisolo (2001, p. 113) destaca o valor da emoção sobretudo na construção do gosto esportivo, como motivo para a ação dos indivíduos, ao expor que,

Se a atividade proposta é um tédio e não cruza com os sonhos, apenas a repressão fará que os estudantes participem. Se a participação é determinada pela obrigação normativa, podemos obter como resposta a presença ausente, participação muito pequena, com 'p' minúsculo. Estou dizendo então que o esporte lida com o estético, com gostos e emoções, do corpo e da performance esportiva, e que não podemos esquecer essa dimensão, talvez hoje a principal.

\footnotetext{
${ }^{6}$ Segundo Schneider e Bueno (2005) o estatuto epistêmico da Educação Física diferencia-se das demais disciplinas uma vez que as formas de aprender e as apropriações passam por outras relações com o saber. Conforme Schneider e Bueno (2005, p. 40-41) "Seus saberes não tomam forma de saberes-objetos, mas inscrevem-se como saberes de regulação, relacionais para consigo mesmo e para com os outros".
} 
Os documentos que definem o perfil do PEC não contemplam esses estados anímicos. A diversão ou o entretenimento excitante não eram objetivos da intervenção, embora sejam dimensões fundantes da atividade esportiva. Nos anos iniciais, o projeto subestimou o ensino das técnicas e fundamentos das diferentes modalidades esportivas, com o argumento de que a ênfase nesses aspectos contribuiria para a seleção dos mais talentosos e para a exclusão dos menos aptos.

Cresceu e se instalou um descompasso entre os objetivos dos gestores e os dos participantes, que se desenvolviam como pessoas cooperativas no processo de aprendizagem das técnicas esportivas:

O objetivo inicial do PEC, que era promover a leitura crítica da realidade social, não se manifestou no discurso dos entrevistados como saber adquirido no projeto. Os discursos e práticas que encontramos evidenciaram que, diferentemente de gerar a exclusão e a seletividade, a aquisição de técnicas esportivas fornece aos participantes metas, objetivos e percepção do desenvolvimento pessoal e coletivo do grupo que participava do projeto (MELLO, 2007, p. 89-90).

Participantes e evadidos ressaltaram as competições como um meio de avaliação do aprendizado/domínio das modalidades esportivas, a figura do aprender que eles tinham como referência. Para compreendermos as práticas e as representações que eles atribuíam às competições esportivas, indagamos: você já participou de alguma competição esportiva pelo PEC? Você acha que o PEC deveria valorizar a participação em competições esportivas? Por quê?

Dentre os 69 evadidos, 33 participaram de competições esportivas e, para 22 deles, as competições desenvolvem o aprendizado da modalidade e validam a técnica adquirida: "Porque vai ensinar a pessoa a nadar, pessoas que nunca participaram de competições para ir desenvolvendo o nado". 
Dezoito evadidos consideram as competições importantes para seu desenvolvimento na modalidade, para verificar a aptidão adquirida e os limites individuais: "É bom para ver a capacidade de cada um". Igual número ressaltou o papel motivacional da competição: "É bom, os alunos têm uma motivação a mais para participar".

Para onze evadidos, a competição contribui na carreira esportiva. Competindo, eles garantem visibilidade a seu talento. Ela dá acesso a eventos e contextos esportivos promissores: "Pode vir pessoas de fora, ver que aquela pessoa é boa, aí pode chamar para competir em outros lugares, aí a pessoa vai ficando importante [...]".

Dos quatorze participantes, dez haviam se envolvido em competição pelo PEC. Entretanto, mesmo os quatro que nunca competiram ressaltaram a sua importância. A possibilidade de competir em outros lugares e a visibilidade que o esporte proporciona são os fatores motivacionais referendados com maior evidência para priorizar a competição.

A competição esportiva é apresentada como uma forma de alcançar mobilidade social e regional: "Competir melhor, em outros lugares, por exemplo, sair daqui para outro lugar". Alguns participantes associam a posição à avaliação do processo, ressaltando a competição como fator crítico para conservar o interesse dos alunos no projeto: "[...] se a gente não tiver competições, a gente só vai ficar treinando, treinando [...] aí a gente vai se desinteressar, não vai gostar mais".

Na perspectiva da análise crítica do discurso, podemos afirmar que parte substancial dos discursos dos entrevistados possui significado identificacional, pois está relacionada com a construção da identidade dos atores. Esses discursos são marcados por afirmações avaliativas, são centrados em expressões circunstanciais, como "competir melhor", e com predomínio de verbos de processos mentais afetivos, como "não vai gostar mais".

Vê-se, portanto, que a perspectiva dos entrevistados era conflitante com a proposta pedagógica do projeto, em que a ênfase das intervenções recaía sobre a construção de discursos críticos e 
restritivos em relação ao uso das atividades físicas e esportivas. As intervenções eram concebidas como formas que buscavam instrumentalizar os participantes para o processo de transformação social, representação que não era compartilhada pelos usuários do projeto.

Os saberes relacionais incluem-se noutra figura do aprender, a atenção para a diferença, que é mencionada e valorizada pelos participantes e evadidos em suas experiências com as atividades esportivas desenvolvidas no projeto. Com efeito, as formas relacionais identificadas nos discursos e nas práticas dos entrevistados evidenciaram a presença da categoria orientação para as diferenças. Essa categoria interpretativa situa-se na dinâmica de interação discursiva em seu aspecto acional (FAIRCLOUGH, 2001). Os conceitos de identidade e diferença estabelecem entre si uma estreita relação de interdependência, traduzindo conflitos de poder entre grupos assimetricamente situados (RESENDE; RAMALHO, 2006).

A diversidade de identidades, marcadas na heterogeneidade das práticas discursivas, encontra três cenários para negociação das diferenças: os discursos que demarcam essas diferenças, os que ignoram e os que buscam minimizá-las (FAIRCLOUGH, 2001). Nas falas de jovens, verifica-se a construção identitária fundamentada na atenuação das diferenças, com ênfase na cooperação, no respeito e na solidariedade

Evadido 1: Não apenas natação [...] mas sim, às vezes, trabalhar mais em conjunto com as pessoas, ficar mais amigo [...].

Evadido 2: Também conheci novas pessoas, aprendi a ter respeito $[\ldots]$.

Participante 1: A convivência com as pessoas diferentes, que eu não tinha. Aqui, no projeto, pude estar interagindo com outras pessoas, divertindo, conversando mais. 
Participante 2: [...] a gente deve tratar as pessoas igualmente, mesmo que elas sejam diferentes. Por que aqui tem turma para cegos, mesmo que eles sejam assim [...], pessoas cegas, também podem nadar.

A procura pelo PEC e a permanência dos participantes no espaço do projeto acontecia tanto em função da necessidade que muitos sentiam de assegurar um momento de atividade física realizada em grupo, quanto das relações que poderiam ser constituídas durante as atividades. São dispositivos relacionais, como figuras do aprender, que somente podem ser construídos com o outro e que se apresentam como "[...] aprender a ser solidário, desconfiado, responsável, paciente [...], a mentir, a brigar, a ajudar os outros [...]" (CHARLOT, 2000, p. 70) que fazem parte dos processos epistêmicos da relação com saber e, nesse caso,

[...] Trata-se dessa vez, porém, de dominar uma relação com os outros e reciprocamente. Aprender é tornar-se capaz de regular essa relação e encontrar a distância conveniente entre si e os outros, entre si e si mesmo; e isso, em situação (CHARLOT, 2000, p. 70).

Em consonância com Charlot, o PEC mostrou que a aprendizagem deve ter sentido e significado para os alunos. O sentido está vinculado ao propósito de cada ação vivenciada, enquanto o significado diz respeito a os valores que cada um atribui à aprendizagem decorrente da ação, porque não há mobilização intelectual sem o desejo e sem a perspectiva do prazer e da satisfação. Uma pessoa somente encontra sentido quando algo que lhe acontece pode ser posto em relação com outras dimensões de sua vida (CHARLOT, 2000).

Diante desse contexto, de conflito entre os objetivos do projeto e o dos participantes, é importante destacar que o movimento de saída e voz dos participantes iniciou um processo de reformulação da proposta inicial do PEC. A abordagem crítica realizada nos anos iniciais do projeto, que considerava o treinamento e as competições esportivas como elemento de exclusão dos menos aptos e habilidosos, 
colidia com a relação que os participantes estabeleceram com os diferentes tipos de esporte. Parte apreciável da evasão entre os jovens ocorria em decorrência da proposta pedagógica adotada pelo projeto. Constatamos que o aprender possuía significados distintos para os agentes e para os participantes do projeto. Quando indagados sobre os motivos da saída, 30\% alegaram desânimo, desinteresse, aulas monótonas e a falta de competitividade. Embora $70 \%$ dos evadidos tenham citado outros motivos, como estudo, trabalho e questões pessoais, para justificar a saída do projeto, temos a hipótese de que parcela significativa desses sujeitos utilizam estratégias discursivas, pautadas em questões moralmente inquestionáveis (RAMALHO; RESENDE, 2006, p. 68), para "[..] salvar a face quando pressionados a falar".

O baixo índice de retenção e a alta rotatividade dos participantes foram decisivos para a mudança de foco do projeto. Esses índices forneceram pistas sobre a insatisfação dos participantes com a proposta adotada pelo projeto, bem como sobre a ausência de um lugar próprio de autoria individual e coletiva. Foi necessário avançar para além das maneiras e artes de fazer astuciosas produzidas pelos praticantes do projeto, a fim de estabelecer estratégias que permitissem a institucionalização, por parte dos participantes do PEC, de novos lugares onde suas vozes se fizessem ecoar, e onde pudessem empoderar-se, desautorizando, assim, os ideais de formação elaborados pelos autores do PEC.

Houve, então, uma gradativa abertura para treinamento e participação em competições esportivas, em função das expectativas e interesse dos participantes. Em outro estudo sobre o PEC, uma das professoras do programa assim sumarizou a urgência de reorientar o projeto:

É preciso modificar o projeto, atender ao que os alunos querem, fazer como eu mesma estou fazendo, lidando com a competição, atraindo mais alunos e os próprios estagiários da universidade, que vêm participar e melhorar a equipe (MELLO, 2007, p. 97). 
Os saberes mobilizados pela professora para atuação no PEC levaram em consideração a relação com os outros, principalmente com os participantes do projeto. Nas relações dialógicas que estabeleceu com os adolescentes e jovens, ela criou acordos para a prática de atividades esportivas. Os saberes pedagógicos necessários à intervenção foram constituídos na sua prática docente.

A atenção ao movimento de saída e de voz possibilitou aos dirigentes do projeto perceber os conflitos nos significados distintos atribuídos às práticas esportivas pelos participantes e agentes do projeto em sua relação com o saber. Gradativamente, de maneira discreta e não linear, o PEC foi ajustando a sua perspectiva pedagógica, na intenção de assegurar que as expectativas dos participantes fossem atendidas e valorizadas na intervenção pedagógica. Esse procedimento alterou para $20 \%$ o índice de retenção dos participantes de um ano para outro.

\section{Considerações Finals}

A forma como o fenômeno esportivo foi consumido no PEC permite inferir que as aprendizagens realizadas por meio do esporte não são necessariamente alienantes. Os jovens sabiam o que esperavam do projeto e possuíam expectativas em relação ao que aprenderiam participando. Quando perceberam que não vivenciariam as experiências esperadas, entre elas a da competição, pressionaram a coordenação para que houvesse mudanças e/ou saíram.

O estudo ratifica o pensamento de Silva (2007, p. 8), citando Parlebas, de que "[...] o desporto não possui nenhuma virtude mágica. Ele não é em si nem socializante, nem anti-socializante [...]. Ele é aquilo que se fizer dele". A competição também não é boa, nem má; ela é aquilo que fazemos dela: instrumento para outras aprendizagens, crítico ou acrítico; estímulo para participação, cooperação, compreensão e produção de estados de solidariedade. Depende do uso que dela for feito pelos autores sociais. 
As representações de evadidos e perseverantes do PEC sobre os motivos de evasão e de adesão e sobre o papel da competição esportiva indicam que havia conflito entre a proposta pedagógica adotada e os sentidos que os jovens construíam para sua ação. Dar "voz" aos sujeitos foi um meio de exercitar as competências argumentativas para que as diferentes comunidades discursivas estabelecessem suas especificidades. Para tanto, os processos formativos migraram de uma concepção em que os conhecimentos são externamente orientados para uma lógica que valorizou as racionalidades locais, construídas a partir das relações que os sujeitos estabeleceram com o objeto do saber.

Os jovens não procuraram o PEC pensando no mundo do trabalho ou na formação da consciência crítica. Em uma sociedade em que as tensões desagradáveis são persistentes, a competição, na forma como é anunciada pelos participantes, é uma possibilidade para a produção de outro estado de emoções que permita a sua liberação autocontrolada. Em vez de reprodução ou adaptação às regras, verificamos participação produtiva segundo as estratégias propostas pelo projeto em relação às táticas de subversão dos participantes que decidiram abandonar ou permanecer no PEC. Concluímos que algum grau de competição convive bem com outras aprendizagens em curso, como a compreensão das diferenças, saber necessário na contemporaneidade. 
Physical Education and Sports: Reflections and Contemporary Actions

Abstract: The article analyzes the way the subjects are appropriated of the sport, highlighting the possibilities to understand the relations with the sports practices. To do so, 83 subjects were interviewed, 69 evaded, and 14 participants of a social project. The analysis indicates that the participants accepted, for a limited period, or even rejected the project proposal, based on the critical-surpassing conception. Not only the reproduction is notable, neither the rules adaptation, but a use that enabled the productive participation made in the dialectic of the strategies imposed by the project, related to subversion tactics of the participants who decided to abandon it or to remain in it.

Keywords: Sports. Physical Education. Reflections. Actions.

\footnotetext{
Educación Física y Deporte: Reflexión y Acciónes Contemporaneas

Resumen: El archivo analiza lo modo como los sujetos se apropian del deporte, señalizando otras posibilidades para comprender las relaciones con las prácticas deportivas. Para eso, entrevista 83 sujetos, 69 evadidos y 14 participantes de un proyecto social. La análisis indica que los participantes aceptaron, por tiempo limitado, o mismo rechazaron la propuesta del proyecto, fundamentada en la concepción críticosuperadora. Se puede percibir que no solamente la reproducción, ni tampoco la adaptación a las reglas, pero un uso que permitió la participación productiva realizada en la dialéctica de las estrategias impostas por lo proyecto, en relación a las tácticas de subversión de los participantes que decidieron abandónalo o permanecer en lo mismo.

Palabras-clave: Deportes. Educación Física. Reflexiones. Acciones.
} 


\section{REFERÊNCIAS}

ALTHUSSER, L. Aparelhos ideológicos de estado: notas sobre os aparelhos ideológicos de Estado. Rio de Janeiro: Graal, 1985.

BOURDIEU, P.; PASSERON, J. C. A reprodução: elementos para uma teoria do sistema de ensino. Rio de Janeiro: Francisco Alves, 1982.

BRACHT, V. "A criança que pratica esporte respeita as regras do jogo... capitalista". Revista Brasileira de Ciências do Esporte, Campinas, v. 7, n. 2, p. 62-68, jan. 1986.

BRACHT, V. Educação física e aprendizagem social. Porto Alegre: Magister, 1992.

CERTEAU, M. de. A invenção do cotidiano: as artes de fazer. Petrópolis: Vozes, 1994.

CHARLOT, B. Da relação com o saber: elementos para uma teoria. Porto Alegre: Artimed, 2000.

. Ensinar a educação física ou ajudar o aluno a aprender o seu corposujeito? In: DANTAS JUNIOR, H. S.; KUHN, R.; RIBEIRO, S. D. D. Educação física, esporte e sociedade: temas emergentes, São Cristóvão, v. 3, p. 231-246, 2009.

CHARTIER, R. A ordem dos livros: leitores, autores e bibliotecas na Europa entre os séculos XIV e XVIII. Brasília: Editora da UNB, 1994.

ELIAS, N.; DUNNING, E. A busca da excitação. Lisboa: DIFEL, 1987.

ELIAS, N. O processo civilizador: uma história dos costumes. Rio de Janeiro: Zahar, 1994.

FAIRCLOUGH, N. Discurso e mudança social. Brasília: Editora da UNB, 2001.

FERREIRA NETO, A. O contexto de produção de "educação física no Brasil: a história que não se conta". In: FERREIRA NETO, A. (Org.). Pesquisa histórica na educação física brasileira. Vitória: CEFD, 1996. p. 189-229.

FOUCAULT, M. Vigiar e punir: história da violência nas prisões. Petrópolis: Vozes, 1987.

HIRSCHMAN, A. Saída, voz e lealdade: reações ao declínio de firmas, organizações e estados. São Paulo: Perspectiva, 1973.

LOVISOLO, H. R. Mediação: esporte rendimento e esporte da escola. Movimento, Porto Alegre, v. 7, n. 15, p. 107-118, dez. 2001.

MEDINA, J. P. S. A educação física cuida do corpo... e "mente". Campinas: Papirus, 1983. 
MELLO, A. S. Projeto Esporte Cidadão: avaliação e reorientação. 2007. 164 f. Tese (Doutorado em Educação Física) - Universidade Gama Filho, Rio de Janeiro, 2007.

RESENDE, V. M.; RAMALHO, V. Análise de discurso crítica. São Paulo: Contexto, 2006.

SCHNEIDER, O. Entre a correção e a eficiência: mutações no significado da educação física nas décadas de 1930 e 1940: um estudo a partir da revista Educação Physica. Revista Brasileira de Ciências do Esporte, Florianópolis, v. 25, n. 2, p. 39-54, 2004.

SCHNEIDER, O.; BUENO, J. G. S. A relação dos alunos com os saberes compartilhados nas aulas de educação física. Revista Movimento, Porto Alegre, v. 11, n. 1, p. 23-46, jan./abr. 2005.

SILVA, F. S. Projetos sociais em discussão na psicologia do esporte. Revista Brasileira de Psicologia do Esporte, São Paulo, v. 1, n. 1, p. 1-12, dez. 2007.

SOARES, C. L. et al. Metodologia do ensino de educação física. São Paulo: Cortez, 1992.

STIGGER, M. P.; LOVISOLO, H. Esporte de rendimento e esporte na escola. Campinas: Autores Associados, 2009.

VAN DIJK, T. A. El discurso como interacción social. Barcelona: Editorial Gedisa, 2000.

VAZ, A. F. Técnica, esporte, rendimento. In: STIGGER, M. P.; LOVISOLO, H. Esporte de rendimento e esporte na escola. Campinas: Autores Associados, 2009. p. 135-156.

WODAK, R.; MEYER, M. (Org.). Methods of critical discourse analysis. London; Thousand Oaks; New Delhi: Sage Publications, 2001.

Endereço para correspondência:

Andre da Silva Mello

Rua Joaquim Lírio, n. 220, apt. 602 -

Praia do Canto - Vitória/ES

CEP: 29055 - 460

Recebido em: 26.11.2010

Aprovado em: 16.06.2011 
